\title{
EFFECT OF PRECEDING RABI CROPS ON YIELD OF SUCCEEDING DESHI AND TOSSA JUTE
}

\author{
M. A. Khan'1, S. M. A. Hossain², M. Jahiruddin ${ }^{3}$, M. Salim², and M.A. Hossain4 \\ 1Jute Research Regional Station, BJRI, Rangpur, ${ }^{2}$ Department of Agronomy and \\ ${ }^{3}$ Department of Soil Science, BAU, Mymensingh, ${ }^{4}$ Pulses Research Center, BARI, Joydebpur, Gazipur. \\ Correspondence author: drmakhan3263@yahoo.com
}

Key words: Rabi crops, deshi and tossa jute, yield

\begin{abstract}
An experiment was conducted at the Jute Research Regional Station, Kishoreganj of Bangladesh Jute Research Institute, during 2001-2002 and 2002-2003 to find out the effects of preceding crops, viz. wheat, potato, lentil, and fallow on yield of succeeding jute crops. The experiment was laid out in a randomized complete block design with four replications. The results revealed that plant height and base diameter of CVL-1 and O9897 were not affected significantly by the preceding rabi crops. The fibre and stick yields of both the jute varieties were affected significantly. The highest fibre yield of CVL1 (3.90 tha $\mathrm{t}^{-1}$ and $\left.3.77 \mathrm{t} \mathrm{ha}^{-1}\right)$ and $0-9897$ (3.51 t ha-1 and $2.93 \mathrm{t} \mathrm{ha}^{-1}$ ) was recorded when those were grown after potato and the yield was the lowest when grown after wheat and fallow land in both the years. There was no sharp variation in harvest index, which showed inconsistent between the years.
\end{abstract}

\section{Introduction}

The framers of Bangladesh grow jute as a cash crop. There are about 0.40 million hectares of land cultivated under jute in Bangladesh (BJRI, 1998). Jute crops usually grow in high, medium high and medium low land. In these lands, there are large numbers of field crops grown in rabi season. Among them wheat, potato, pulse crop etc. are very common. Jute crop generally sown immediate after harvest of rabi crops. These rabi crop by their nature affected by the preceding crops. Besides, the farmers cultivated rabi crop by using different level of organic and inorganic fertilizers. Traditionally the farmers have been using over doses of chemical fertilizers in potato crops and no fertilizer use in pulse crops. The residual fertilizer of previous crops can affect the subsequent crop. Khan et al. (1998) reported that the better performance of jute crop was observed after potato cultivating compared to that after wheat.

The preceding legume crops positively influenced the yield as well as economics of subsequent rice compared to fallow and wheat (Chandra and Gautam, 1997). Quayyum and Maniruzzaman (1996) reported that when rice crop preceded by sole blackgram, it produced significantly high yield. Khan et al. (2007) also reported that transplant aman rice produced significantly higher yield, when it was preceded by dhaincha (Sesbania aculeata) and jute compared to than that of transplant aus rice and fallow. Ahlawat et al. (1991) observed the beneficial effect of legume in the crop rotation. Jain and Solanki (1993) reported that the legumes like blackgram and groundnut growing as preceded to opium poppy improved the latex yield of poppy compared to maize. Satayanarayana and Arora (1984) reported that the yield of onion bulb increased substantially when potato crop preceded it. These findings revealed that the productivity of different crops influenced by the preceding crops. Therefore, the present study was carried out to assess the effects of preceding rabi crops on yield and yield attributes of deshi and tossa jute. 
Khan et al.

\section{Materials and Methods}

The experiment was conducted at the Jute Research Regional Station of Bangladesh Jute Research Institute (BJRI), Kishoreganj in 2001-2002 and 2002-2003. The soil of experimental plot was silt loam in texture, slightly acidic ( $\mathrm{pH} 6.75)$, low in organic matter (1.52\%), total nitrogen $(0.085 \%)$ and exchangeable potassium $\left(0.08\right.$ meq. $\left.100 \mathrm{~g}^{-1}\right)$, had optimal level of phosphorus (17.0 ppm) and available sulphur near about critical level $(14.0 \mathrm{ppm})$. In rabi season, the crops, viz. wheat, potato, lentil were grown and kept fallow in randomized complete block design with four replications following recommended management practices for the respective crops. After harvest of rabi crops, each plot was divided into two equal halves for growing deshi and tossa jute. The varieties CVL-1 of deshi jute and O-9897 of tossa jute were used as study materials. The unit plot size for individual jute crop was $4 \mathrm{~m} \times 5 \mathrm{~m}$. The fertilizer was applied at the rate of 45.0-5.0-22.5-8.0 kg ha-1 and 90.0-10.0-45.0-8.0 kg ha-1 N-P-K-S for CVL-1 and O-9897, respectively as per recommended practices. The rabi crops sown on 12.12 .2001 and 29.11.2002. After the harvest of rabi crops, the jute crops sown on 18.4.2002 and 15.4.2003. The seed rates were used as $7.0 \mathrm{~kg} \mathrm{ha}^{-1}$ and $5.0 \mathrm{~kg} \mathrm{ha}^{-1}$ respectively for CVL-1 and O-9897. Jute crop was harvested at 120 days after sowing. At harvest, $1 \mathrm{~m}^{2}$ area of each treatment was harvested from $20 \mathrm{~m}^{2}$ plot for recording plant population. The plant height and base diameter were recorded from 10 randomly selected plants. Fibre and stick yield were recorded from whole plot.

The collected data were statistically analyzed following Gomez and Gomez (1984). The computer package IRRISTAT was made for analysis of variance for the data of different parameters. Differences among the means were computed for significance following the LSD test.

\section{Results and Discussion}

\section{Effects of preceding rabi crops on yield and yield parameters of jute \\ Plant population}

Plant population in per unit area is the important factor for fibre yield of jute. It directly affects the fibre yield. In this study plant $\mathrm{m}^{-2}$ in deshi jute was not varied significantly in the first year but in second year, it was varied significantly by the preceding crops (Table 1 ). In first year plant $\mathrm{m}^{-2}$ was recorded 34.6 to 36.6 and in second year the highest number of plants $\mathrm{m}^{-2}$ (42.7) was recorded when the CVL-1 was preceded by potato, which was followed by lentil (39.8). The lowest number of plants $\mathrm{m}^{-2}$ (37.5) was observed when jute grown after wheat. This result was similar to that when jute grown after the fallow land. In case of tossa jute, plant $\mathrm{m}^{-2}$ was not affected significantly by the preceding crops. Plant $\mathrm{m}^{-2}$ of tossa jute was recorded 28.6 to 31.4 and 34.5 to 37.5 , respectively in the first year and second year.

\section{Plant height and base diameter}

The plant height and base diameter of deshi (CVL-1) and tossa jute (O-9897) were not affected significantly due to different preceding crops in both the years (Table 1). The numericaly higher plant height of CVL-1 and O-9897 was observed when the jute was grown after potato, which was followed by lentil and it was lower when grown after wheat and fallow plot in both the year. Similar results were also observed in case of base diameter. The higher base diameters were recorded when jute grown after potato and lentil, and lower than that of wheat and fallow in both 
Preceding Rabi Crops effects on Succeeding Deshi and Tossa Jute

the year. The higher plant height and base diameter might be influenced the fibre and stick yield of jute.

\section{Fibre yield}

The fibre yield of CVL-1 (deshi) and O-9897 (tossa) was affected significantly due to preceding crops (Table 2). The highest fibre yields of $3.90 \mathrm{t} \mathrm{ha}^{-1}$ and $3.61 \mathrm{t} \mathrm{ha}^{-1}$ were recorded in CVL-1 when it was preceded by potato and lentil, respectively in the first year. The lowest fibre yield (3.02 $\mathrm{t} \mathrm{ha}^{-1} 3.02 \mathrm{t} \mathrm{ha}^{-1}$ ) was observed in CVL-1 when it was grown after keeping the land fallow and wheat. In the second year the result was similar to that of first year. Similarly, the highest fibre yield of $3.51 \mathrm{t} \mathrm{ha}^{-1}$ was recorded from $0-9897$ when it was preceded by potato in the first year. The second highest (2.95 $\left.\mathrm{t} \mathrm{ha}^{-1}\right)$ fibre yield was recorded when grown after lentil. The lower fibre yield (2.55 $\mathrm{t} \mathrm{ha}^{-1}$ ) was recorded in $\mathrm{O}-9897$ when it was preceded by wheat and fallow land $\left(2.53 \mathrm{t} \mathrm{ha}^{-1}\right)$. In the second year, a similar result was also observed.

\section{Stick yield}

Stick yield of CVL-1 was significantly affected by the preceding rabi crops in both the years (Table 2). In the first year, the highest stick yield of $7.73 \mathrm{t} \mathrm{ha}^{-1}$ was recorded when CVL-1 was grown after potato, which was followed by $6.90 \mathrm{t} \mathrm{ha}^{-1}$ when grown after lentil. The lowest stick yields of $6.50 \mathrm{t} \mathrm{ha}^{-1}$ and $6.08 \mathrm{t} \mathrm{ha}^{-1}$ were recorded when CVL-1 was grown after fallow and wheat, respectively. A similar result was also observed in the second year. Stick yield of O-9897 was significantly affected by the preceding rabi crops in the first year but there was no significant variation in the second year. The highest stick yield $\left(7.08 \mathrm{t} \mathrm{ha}^{-1}\right)$ was recorded when $0-9897$ was grown after potato, which was followed by yield of $6.07 \mathrm{t} \mathrm{ha}^{-1}$ when grown after lentil in the first year. The lowest stick yield of $5.38 \mathrm{t} \mathrm{ha}^{-1}$ and 5.33 tha $^{-1}$ were recorded when $0-9897$ grown after fallow land and wheat, respectively.

\section{Harvest Index}

Harvest index of CVL-1 ranged from 32.4 to 34.4 and 31.6 to 34.2 in the first year and second year, respectively (Table 2). The highest harvest index (HI) was observed when CVL-1 grown after lentil (34.4) and potato (33.5). In contrast the HI (32.4 and 31.9) was the lowest when the crop grown after fallow land. The harvest index of O-9897 varied from 32.2 to 33.1 in the first year and 30.6 to 31.2 in the second year. The higher harvest index was observed in 0-9897 when planted after potato and lentil.

Table1. Plant height and base diameter of deshi and tossa jute as affected by preceding crops

\begin{tabular}{|c|c|c|c|c|c|c|c|c|c|c|c|c|}
\hline \multirow{3}{*}{$\begin{array}{l}\text { Preceding } \\
\text { crops }\end{array}$} & \multicolumn{4}{|c|}{ Plant $\mathrm{m}^{-2}$ (no.) } & \multicolumn{4}{|c|}{ Plant height (m) } & \multicolumn{4}{|c|}{ Base diameter $(\mathrm{mm})$} \\
\hline & \multicolumn{2}{|c|}{ deshi } & \multicolumn{2}{|c|}{ Tossa } & \multicolumn{2}{|c|}{ deshi } & \multicolumn{2}{|c|}{ tossa } & \multicolumn{2}{|c|}{ deshi } & \multicolumn{2}{|c|}{ tossa } \\
\hline & $\begin{array}{c}2001- \\
02\end{array}$ & $\begin{array}{c}2002- \\
03\end{array}$ & $\begin{array}{c}2001- \\
02\end{array}$ & $\begin{array}{c}2002- \\
03\end{array}$ & $\begin{array}{c}2001- \\
02\end{array}$ & $\begin{array}{c}2002- \\
03\end{array}$ & $\begin{array}{c}2001- \\
02\end{array}$ & $\begin{array}{c}2002- \\
03\end{array}$ & $\begin{array}{c}2001- \\
02\end{array}$ & $\begin{array}{c}2002- \\
03\end{array}$ & $\begin{array}{c}2001- \\
02\end{array}$ & $\begin{array}{c}2002- \\
03\end{array}$ \\
\hline Wheat & 36.6 & 37.5 & 30.3 & 37.5 & 2.96 & 2.85 & 3.01 & 2.78 & 15.8 & 15.8 & 14.0 & 12.9 \\
\hline Potato & 36.6 & 42.7 & 28.6 & 36.9 & 3.19 & 3.02 & 3.17 & 2.89 & 17.0 & 17.5 & 15.3 & 13.9 \\
\hline Lentil & 35.5 & 39.8 & 29.3 & 34.5 & 3.27 & 2.91 & 3.20 & 2.84 & 16.9 & 16.2 & 15.1 & 13.8 \\
\hline Fallow & 34.6 & 39.1 & 31.4 & 35.9 & 3.00 & 2.87 & 3.04 & 2.57 & 15.7 & 15.3 & 14.2 & 12.0 \\
\hline $\operatorname{LSD}_{(0.05)}$ & NS & 5.0 & NS & NS & NS & NS & NS & NS & NS & NS & NS & 1.4 \\
\hline CV (\%) & 9.7 & 7.8 & 7.6 & 7.8 & 3.2 & 4.6 & 3.4 & 6.7 & 7.4 & 8.8 & 5.4 & 6.5 \\
\hline
\end{tabular}


Khan et al.

Table 2. Fibre yield, Stick yield and harvest index of deshi and tossa jute as affected by preceding crops

\begin{tabular}{|c|c|c|c|c|c|c|c|c|c|c|c|c|}
\hline \multirow{3}{*}{$\begin{array}{l}\text { Preceding } \\
\text { crops }\end{array}$} & \multicolumn{4}{|c|}{ Fibre yield $\left(\right.$ tha $\left.^{-1}\right)$} & \multicolumn{4}{|c|}{ Stick yield (tha-1) } & \multicolumn{4}{|c|}{ Harvest Index (\%) } \\
\hline & \multicolumn{2}{|c|}{ deshi } & \multicolumn{2}{|c|}{ Tossa } & \multicolumn{2}{|c|}{ deshi } & \multicolumn{2}{|c|}{ tossa } & \multicolumn{2}{|c|}{ deshi } & \multicolumn{2}{|c|}{ tossa } \\
\hline & $\begin{array}{c}2001- \\
02\end{array}$ & \begin{tabular}{|c|}
$2002-$ \\
03
\end{tabular} & $\begin{array}{c}2001- \\
02\end{array}$ & $\begin{array}{c}2002- \\
03\end{array}$ & $\begin{array}{c}2001- \\
02\end{array}$ & $\begin{array}{c}2002- \\
03\end{array}$ & $\begin{array}{c}2001- \\
02\end{array}$ & $\begin{array}{c}2002- \\
03\end{array}$ & $\begin{array}{c}2001- \\
02\end{array}$ & $\begin{array}{c}2002- \\
03\end{array}$ & $\begin{array}{c}2001- \\
02\end{array}$ & $\begin{array}{c}2002- \\
03\end{array}$ \\
\hline Wheat & 3.12 & 2.97 & 2.55 & 2.50 & 6.08 & 6.43 & 5.38 & 5.70 & 33.9 & 31.6 & 32.2 & 30.7 \\
\hline Potato & 3.90 & 3.77 & 3.51 & 2.93 & 7.73 & 7.27 & 7.08 & 6.47 & 33.5 & 34.2 & 33.1 & 31.2 \\
\hline Lentil & 3.61 & 3.27 & 2.95 & 2.63 & 6.90 & 6.93 & 6.07 & 5.93 & 34.4 & 32.1 & 32.7 & 30.7 \\
\hline Fallow & 3.02 & 2.70 & 2.52 & 2.40 & 6.50 & 5.77 & 5.33 & 5.67 & 32.4 & 31.9 & 32.4 & 30.6 \\
\hline $\operatorname{LSD}_{(0.0}$ & 0.39 & 0.40 & 0.34 & 0.09 & 0.72 & 0.70 & 0.86 & NS & - & - & 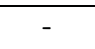 & - \\
\hline CV (\%) & 7.1 & 8.0 & 7.1 & 7.2 & 6.6 & 6.7 & 9.0 & 7.3 & & & & \\
\hline
\end{tabular}

Traditionally larger amount of fertilizers are used in potato crops to maximize the tuber yield. As a result, a portion of the residual fertilizer remains in the field and that affects the next crop. Khan et al. (1998) reported a better performance of jute grown after potato compared to the jute grown after wheat. The pulse crop like lentil also affected the following jute crop due to residues (root stubbles), which was replenished the soil fertility through biological nitrogen fixation. The lowest fibre and stick yield of jute was recorded, when it was preceded wheat and fallow. Biswas et al. (1971) also reported that wheat crops are heavy consumer of nutrients. The soil nutrients also degrade during fallow period that affects the subsequent crop. Meera et al. (1999) reported that fallowing in summer lead to degradation of soil properties including reduced nutrients availability, which may causes the lower fibre yield of jute. Singh and Ashwathi (1978) also reported that fallowing decreases the soil fertility.

The fibre yield of jute was higher followed by potato crops might be due to the residual effect of fertilizer, which was used in preceding potato crops. In potato crops excessive amount of fertilizer were used to maximize the yield, as a result a portion fertilizer remain in the soil as residues and it affected the succeeding crops. Khan et al. (1998) reported that jute crops after potato cultivation performed better compared to jute after wheat. The pulse crop, lentil also affected the following jute crop due to residues (root stubbles) of lentil, which was replenished the soil fertility through biological nitrogen fixation in the soil. The lowest fibre and stick yield of jute were recorded, when it was preceded wheat and fallow

\section{Conclusion}

In conclusion, the results of this study indicated that fibre and stick yields of deshi and tossa jute were the highest when jute crops are grown after potato cultivation, followed by lentil. Fibre yield of jute decreased when jute crops are grown after wheat and fallow.

\section{References}

Ahlawat, I. P. S., A. Singh and C. S. Saraf. 1991. Effect of winter legumes of the nitrogen economy and productivity of succeeding cereal. Expt. Agric. 15: 57-62.

Biswas, T. C., B. L. Jain and S. C. Mandal. 1971. Cumulative effect of different leaves of manures on the physical properties of soil. J. Indian Soc. Soil Sci. 19: 31-37.

BJRI (Bangladesh Jute Research Institute). 1998. Jute and Jute Fabrics, Bangladesh. Newsl. BJRI. 24: 2-5. 
Preceding Rabi Crops effects on Succeeding Deshi and Tossa Jute

Chandra, S. and R. C. Gautam. 1997. Effect of preceding crops and nitrogen rates on rice yields and economics of its rotation. Ann. Agric. Res. 18: 454-459.

Gomez, K. A. and A. A. Gomez. 1984. Statistical procedures for Agricultural Research. $2^{\text {nd }}$ Ed. An International Rice Research Institute book, John Wiley and Sons Inc., New York. pp.35-680.

Jain, P. M. and N. S. Solanki. 1993. Effect of preceding crops on fertilizer requirement of opium poppy (Papaver somniferum). Indian J. Agron. 38(1): 105-106.

Khan, M. M. R., M. Ahmed and M. A. Wahab. 1998. Integrated nutrient management with inorganic fertilizers and organic manures for two dominant cropping patterns. Proc. of the National Workshop on Integrated Management for Crop Production and Soil Fertility. 24-25 March, 1998, Bangladesh Agril. Res. Inst. Joydebpur, Gazipur. pp.153-157.

Khan, M. A., S. M. A. Hossain, M. Jahiruddin and M. Salim. 2007. Effects of preceding crops on transplant aman rice productivity and soil fertility. Bangladesh J. Agri. 32: 11-18.

Meera, V., M. V. Menon, M. A. Nair and N. N. Potty. 1999. Effect of summer cropping and fallowing on the productivity of rice lands. J. Trop. Agric. 37: 85-86.

Quayyum, M. A. and A. F. M. Maniruzzaman. 1996. Effect preceding crops on yield of succeeding transplanted aman rice (Oryza sativa). Indian J. Agron. 41: 349-353.

Satyanarayana, V. and P. N. Arora. 1984. Effect of fertilizers on potato and their residual effect on succeeding onion. Indian J. Agron. 29: 309-311.

Singh, K. K. and O. P. Ashwathi. 1978. Maintenance of soil fertility in the hills with incorporation legumes in cropping sequence. Indian J. Agric. Sci. 48: 41-46. 